\title{
Carbon Emission from Urban Passenger Transportation in Beijing
}

\author{
Zijia Wang a,b,c, Feng Chen ${ }^{a, b *}$ and Taku Fujiyama ${ }^{c}$ \\ a School of Civil and Architectural Engineering, Beijing Jiaotong University, No.3 Shangyuancun, \\ Haidian District, Beijing, 100044, P. R. China \\ ${ }^{\mathrm{b}}$ Beijing Engineering and Technology Research Center of Rail Transit Line Safety and Disaster \\ Prevention, No.3 Shangyuancun, Haidian District, Beijing, 100044, P. R. China \\ ${ }^{\mathrm{c}}$ Department of Civil, Environmental and Geomatic Engineering, University College London, \\ Chadwick Building, Gower Street, London WC1E 6BT, England \\ * Author to whom correspondence should be addressed; E-Mail: fengchen@bjtu.edu.cn; \\ Tel.: +86-10-51688070; Fax: +86-10-51688070.
}

\begin{abstract}
Urban passenger transport significantly contributes to global greenhouse gas emissions, especially in developing countries owing to the rapid motorization, thus making it an important target for carbon reduction. This article established a method to estimate and analyze carbon emission from urban passenger transport including cars, rail transit, taxis and buses. The scope of research was defined based on car registration area, transport types and modes, the stages and energy record of rail transit. The data availability and gathering were fully illustrated. A city level emission model for the aforementioned four modes of passenger transport was formulated, and parameters including emission factor of electricity and fuel efficiency were tailored according to local situations such as energy structure and field survey. The results reveal that the emission from Beijing's urban passenger transport in 2012 stood at 15 million tonnes of $\mathrm{CO}_{2}$, of which $75.5 \%$ was from cars, whereas car trips sharing constitutes only $42.5 \%$ of the total residential trips. Bus travel, yielding $28.6 \mathrm{~g} \mathrm{CO}_{2}$, is the most efficient mode of transport under the current situations in terms of per passenger kilometer (PKM) emission, whereas car or taxi trips emit more than 5 times that of bus trips. Although a decrease trend appears, Beijing still has potential for further carbon reduction in passenger transport field in contrast to other cities in developed countries. Development of rail transit and further limitation on cars could assist in reducing 4.39 million tonnes $\mathrm{CO}_{2}$ emission.
\end{abstract}

Keywords: carbon emission; urban passenger transport; model; mode sharing; emission factor 


\section{Introduction}

Human-induced global warming has drawn worldwide concern and this anthropogenic climate change was attributed to greenhouse gas emission (GHG), mainly $\mathrm{CO}_{2}$ emitted through human activities. According to a recently issued report (Olivier, 2013), annual $\mathrm{CO}_{2}$ emission hit a new record high, reaching 34.5 billion tonnes in 2012 , of which $22 \%$ was contributed by the transport sector. As a place of high population concentration and increased human activities, city passenger transport systems consume a lot of energy and are responsible for carbon emission in the transport area to a great extent (He et al, 2005). The multi-modal urban transportation systems include cars, rail transit, buses, and taxis, and carbon emission per passenger per kilometer varies greatly depending on modes. Carbon emission of cars with an acceptable emission factor is $271 \mathrm{~g} \mathrm{CO}_{2} / \mathrm{PKM}$ (passenger-kilometer), which is 3 times that of buses, and 4 times that of metro or light rail (Hodges, 2010; Australian Greenhouse Office, 2007). Therefore, urban passenger transport is one of the largest targets for potential carbon emission reduction due to the possibility of modal shift in terms of total volume. It is necessary to study the calculation method and the structure of urban passenger transport carbon emission to implement effective carbon mitigation strategies or policies.

As the capital of the largest developing country, Beijing has a large number of residential trips and passenger transport infrastructures. According to an annual report of Beijing traffic development (Beijing Transportation Research Center, 2013), until the end of 2012, the residential population of Beijing was 20.693 million, and the corresponding annual trips were 13.07 billion. Furthermore, in 2012, the registered vehicles soared to 5.2 million, of which 4.19 million were private auto, and daily trips of cars reached 9.90 million. There are 22146 buses in operation on 779 bus lines, serving 8.26 million trips every day in average. Urban rail transit in Beijing rapidly developed with the primary aim of mitigating congestion and implementing low-carbon transport policy (Anas et al., 2009). By the end of 2012, the total operation mileage of urban rail reached 442 kilometer (4 lines opened on December 30,2012 ) and 261 stations, and the annual trip segments were 2.46 billion. The mobile source carbon emission for such a large number of trips should be determined with relatively high accuracy.

The study of the calculation of urban transport GHG emissions has long drawn scholarly attention. Researchers have not only done a lot of work in establishing city-level emission models, but also developed a number of practical tools for the calculation of transport carbon emission including MOBILE6, COMMUTER, MOVES, and CMEM (Grant et al., 2008). These methods or tools can be roughly categorized into two classes: top-down approach and bottom-up approach. The former approach estimates total emission through the overall energy consumption, whereas the latter calculates GHG emission for each mode using VKT (vehicle kilometer travelled), energy efficiency, and emission factor. Bottom-up approach requires relatively more detailed data and allows further analysis of results such as evaluation of emission reduction strategies, and thus, is commonly applied in the estimation of city level transport emission. Although various methods have been formulated for the estimation of transport GHG emission, and could be used for carbon emission calculation of city transport, few models specifically calculate city level transport carbon emission. He et al. (2011) developed a city-level transportation energy consumption and carbon emission calculation model suited to local situations of Jinan in China, and analyzed the effect of passenger transport mode split on carbon emission. However, the data resource and some important factors such as the electricity carbon 
emission factor were not well illustrated. Nejadkoorki et al. (2008) established a comprehensive method to calculate the urban road transport $\mathrm{CO}_{2}$ emission by integrating three independent models: traffic assignment model, emission calculation model and emission visualization model, and applied the approach in the United Kingdom. Although this method is well-founded, difficulties arise when applied to China due to lack of vehicle usage data on an origin-destination level and emission factors corresponding to various speed ranges. Kakouei et al. (2012) used a simple model to estimate daily road transport carbon emission in Tehran in 2012, estimated at 29827 tonnes of $\mathrm{CO}_{2}$, by calculating emission of each mode by multiplying VKT, fuel efficiency, and emission factor. Rail transit emission has not been taken into account in their study. Rayle and Pai (2010) projected three kinds of carbon emissions in India in different scenarios and demonstrated the potential for large emission reduction. As projected by the implementation document for international carbon trade of CDM (Clean Development Mechanism) related to mass rapid transit, ACM0016 (Board, 2011) presents a methodology to calculate carbon emission reduction of urban rail and urban road passenger transport. Although the method is used for certified emission reductions, it can be applied to calculate city level passenger transport carbon emission. However, rail station energy consumption such as lighting and environment control system is not taken into account for calculating carbon emission (Board, 2011), possibly because urban rail will not be as energy efficient as generally believed if station energy is counted. A project sponsored by World Bank Group estimated the carbon emission of transportation sector (including freight transportation) in Beijing in 2009 using activity-based method (Beijing Jiaotong University, 2012). Although the work covers rail transit, the methodology is rather simple. A national level emission factor for electricity was used based on a rough estimation because official emission factor for electricity was not published then. The results overestimated the carbon emission from rail by about ten percent. In addition, the study did not acquire enough official data from operation company, such as energy consumption of taxi and bus efficiencies, which affected the method used and the accuracy of the results. The study used officially released vehicle fuel efficiency, which is much higher than actual value, especially under normally low speeds due to congestion.

However, most of methods are not directly applicable in the case of Beijing because of the following reasons. First, most of these tools or models are used for road transport only, whereas energy consumption and carbon emission of rail transit are significant in Beijing and should not be neglected. Second, current methods generally depend on sophisticated data accumulated in developed countries, while data in developing countries is not well compiled and sometimes the statistical standards for the same parameter are quite different. For instance, in China, a rail trip is regarded as a passenger entering a rail system or taking interchange to another line in the system, just as the case in which a bus passenger changes to another bus line, then a new bus trip is generated. While in London, a trip of a specific mode is determined by the mode of the longest travel distance within a linked trip (Transport for London, 2013), such as from home to work, no matter how many modes the trip maker uses. A trip may have several journey stages, which are corresponding to different modes. But even a rail journey stage is quite different to a rail trip in China, because it does not treat any internal interchange in the rail system as a new rail journey stage. Finally, carbon emission of electricity consumption is either computed vaguely or completely neglected in most of the existing research. For instance, projects from World Bank Group used a roughly-estimated national level emission factor for electricity. 
The main purpose of this work was to establish a methodology to estimate and analyze city level carbon emission from passenger transport according to the transport characteristics of metropolitan areas in developing countries. To this end, Beijing has been taken as a case study. The estimation scope has been defined and a carbon emission model has been formulated based on data availability. A method for calculating carbon emission factor of electricity has been formulated considering the shares of various electricity types. Total carbon emission from the passenger transport of Beijing has been estimated through data gathering and parameter localization, such as field-collected vehicle efficiency. Finally, mode sharing of total emission and future reduction potential are discussed. The contribution of this work is instrumental in estimating city level transport carbon emission in developing countries, especially China.

\section{Scope and Data Availability}

Urban passenger transport involves a variety of transport modes, vehicle types, vehicle owners (organizations or individuals), and varying driving ranges in terms of administrative areas for different vehicle types. This results in a large body of statistical data. In addition, the variety of statistical standards and the imperfect traffic statistics system in developing countries make things difficult. All these factors combine to make carbon emission estimation difficult. Calculation should be based on data availability and calculation scope which should be determined based on acceptable accuracy.

\subsection{Calculation Scope Description}

Based on the current emission model and urban passenger transport emission estimations undertaken in other research, and in accordance with the statistical data of Beijing, the calculation scope was defined by the following five aspects.

(1) Only urban passenger transport in Beijing was considered as the transport type. Long-distance passenger transport to or from other provinces, the railway transport, air transport, and other longdistance passenger transport are excluded. However, the local passenger traffic connected to these transport types was covered.

(2) Only vehicles registered in Beijing are considered under vehicle registration location. Non-local vehicles are excluded, even for the usage that occurs in Beijing. There were some inconsistencies for this aspect of the scope. The first one is that the usage of local vehicles out of the boundary is actually included. The second is that the emission generated by non-local vehicles inside the boundary is not covered. Due to the data statistical standards, these inconsistencies could not be determined quantitatively. But considering they can offset each other, the error will be small.

(3) With respect to transport modes, according to the relevant estimation, the $\mathrm{CO}_{2}$ emission of each passenger transport mode can be illustrated from high to low for private or organization owned cars, taxis, buses, rail transit, motorcycles, and electric bicycles. According to traffic management policies and availability of data statistics in Beijing, only the first four modes are covered in this work. Moreover, due to absence of statistical data and difficulty in carrying out special investigation, the few non-profit buses owned by some organization are excluded. However, the urban tourism buses, which are present in large numbers in Beijing, are included for this study.

(4) With regard to calculation stages and emission gases, only direct emissions are considered for non-electric power vehicles. While for rail transit, trolley, and others, emission of fossil fuel electricity 
during the generation stage was also counted corresponding to terminal consumption of fossil fuel in vehicles, according to international CDM projects (UNFCCC/CCNUCC,2011)and domestic practice (National Development and Reform Commission of China,2013). Furthermore, for the purpose of this study, carbon emission refers to $\mathrm{CO}_{2}$, while $\mathrm{CH}_{4}$ and other non- $\mathrm{CO}_{2} \mathrm{GHGs}$ are not involved.

(5) Specifically for rail transit, the power and lighting system energy consumption of stations and corresponding carbon emission are covered. In comparison to road lighting, the power and lighting system energy consumption of rail stations is more, which is equivalent to the traction energy for underground lines, and more importantly, rail transit station is an indispensable part of rail transit (Wang et al., 2013).

\subsection{Data Availability Analysis}

Data availability not only affects the definition of calculation scope to a certain extent, but also determines specific carbon emission calculation methods. Therefore, before establishing the emission model, it is necessary to analyze data availability under the defined calculation scope.

Carbon emission calculation mainly involves vehicle population of all kinds of transport modes, annual mileage travelled, passenger volume, average trip distance, energy efficiency, energy consumption statistics of some modes, and basic parameters of all transport modes such as net calorific value of fuel and carbon emission factors. These data have been obtained from the following sources.

(1) Internal statistical data from the rail transit operation company, and bus and taxi data from the earning cooperation of these companies. The energy consumption of rail transit, passenger volume, and average trip distance information were provided by Beijing Subway Operation Company and Beijing MTR Corporation Limited. The vehicle population of bus, annual mileage travelled, passenger volume, average trip distance, and information on energy efficiency of various types of buses were obtained from the Beijing Public Transport Holdings Limited. We interviewed all the 253 taxi companies and obtained the number of taxi vehicles and total annual energy consumption.

(2) Basic traffic data was cited from transportation statistical report officially released by the Beijing government. Statistical transport data such as average transport distance was obtained from "2012 Beijing traffic development annual report” (Beijing Transportation Research Center, 2013) and "Beijing the $4^{\text {th }}$ comprehensive transport survey" (National Development and Reform Commission of China, 2013), which is published once every five years, and other relevant statistical yearbooks.

(3) Because there was no recorded data on annual VKT and energy efficiency of non-operational car, such data were gathered by questionnaire investigation and stratified random sampling survey. A sample of 2100 respondents was distributed to 15 subpopulations of passenger car in terms of engine displacement. Questionnaires including questions about annual running kilometer and fuel consumption per 100 kilometer were delivered in the main parking lots scattered in the whole city. Finally 2000 valid respondents were received and tailored to get the expected data.

(4) Emission factors were obtained from IPCC 2006 (Intergovernmental Panel on Climate Change, 2006) and other officially published reports. No official data was available in Beijing pertaining to the net calorific value of transportation fuels and carbon emission factor. Therefore, the emission factors used in this work were converted by data obtained from IPCC 2006, and using the following sources: "2013 Baseline Emission Factors for Regional Power Grids in China," (National Development and 
Reform Commission of China, 2013) and "China energy statistical yearbook 2012" (National Bureau of Statistics of China,2012).

\section{Methodology and Data Gathering}

According to the definition of the calculation scope and available data, we can establish a passenger transport carbon emission calculation model, which is also applicable to other cities. The model mechanism of traffic carbon emission calculation is not complex for both the top-down approach as well as the bottom-up approach. The main calculation difficulties are data acquisition and parameter calibration, as well as whether the data statistics standards match each other.

\subsection{Methodology}

Urban passenger transport $\mathrm{CO}_{2}$ emissions are generally estimated with top-down or bottom-up approach according to the mobile emission source measurement methods in the IPCC (2006), as stated above. The former is based on regional transportation fuel sales and $\mathrm{CO}_{2}$ emission factors for each fuel type, whereas the latter is based on VKT, energy efficiency, and $\mathrm{CO}_{2}$ emission factor for each vehicle type. These methods differ in terms of data selection and use. Although the top-down method enables direct and more accurate transport carbon emissions estimation, since total fuel consumption data is not easy to obtain, it is not practical for most situations. Thus, the bottom-up approach is more commonly applied. In cases where the average annual VKT and vehicle fleet energy efficiency data are not available, indirect figures or survey data released by official or authoritative organizations could be taken.

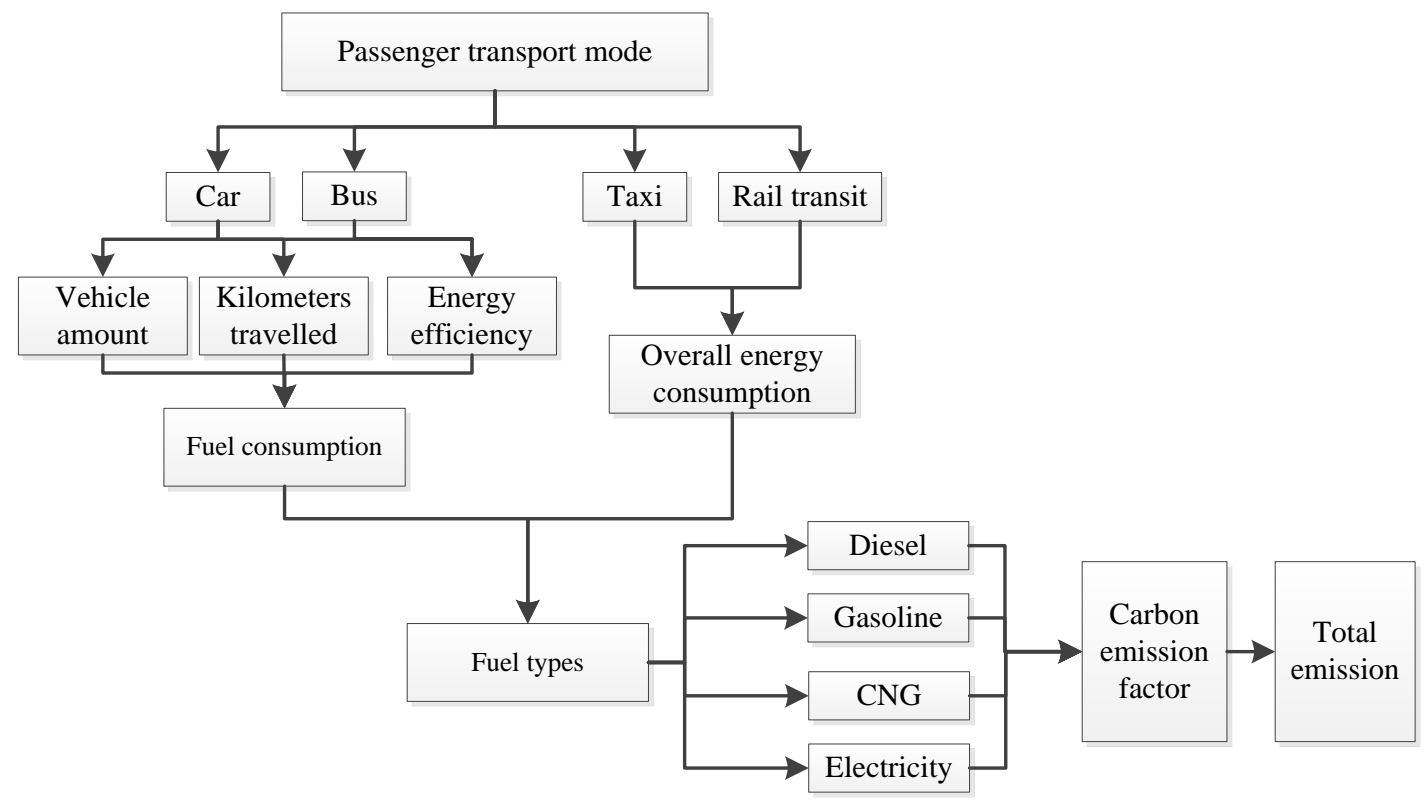

Figure 1. Illustration of urban passenger transport carbon emission model

In conclusion, considering that taxis and rail transit in Beijing have specialized energy consumption statistics, while such statistics are absent for some others, this paper has integrated top-down and bottom-up method of the IPCC moving source emission model to estimate traffic carbon emission in Beijing, as shown in Figure 1. The emission model is demonstrated as follows: 


$$
C e_{p}=\left(N_{c} \cdot T_{c} \cdot F e_{c}+E_{t}+E_{r}+\sum_{i} N_{b, i} \cdot T_{b, i} \cdot F e_{b, i}\right) E f_{j}
$$

Here, $C e_{p}$ denotes the total carbon emission of passenger transportation $\left(\mathrm{kg} \mathrm{CO}_{2}\right)$, and $N_{c}, T_{c}$, and $\mathrm{Fe}_{c}$ are car ownership, average annual VKT $(\mathrm{km})$, and energy efficiency of car $(\mathrm{L} / \mathrm{km})$, respectively. Cars here include private cars and organization owned cars with nine seats or less. $E_{t}$ and $E_{r}$ denote energy consumption of taxi and rail transit, respectively. $N_{b, i}, T_{b, i}$ and $F e_{b, i}$ refer to bus population, average annual VKT $(\mathrm{km})$, and energy efficiency (L/km for gasoline or diesel, $\mathrm{kg} / \mathrm{km}$ for CNG, and $\mathrm{kWh}$ for trolley) of bus type $i$. Currently, there are six bus types in Beijing, including diesel single unit bus, diesel articulated bus, and CNG single unit bus. $E f_{j}$ is the carbon emission factor of fuel type $j$ ( $\mathrm{kg} \mathrm{CO}_{2} / \mathrm{L}$ for gasoline or diesel, $\mathrm{kg} \mathrm{CO} / \mathrm{kg}$ for $\mathrm{CNG}$, and $\mathrm{kg} \mathrm{CO}_{2} / \mathrm{kWh}$ for electricity).

\subsection{Data Gathering and Parameter Calibration}

According to the emission model, emissions can be estimated with two kinds of data. The first type of data, including vehicle population, VKT, energy efficiency, and so on, were accessed from the basic statistics of Beijing's passenger transport. The other data are parameters of various fuels such as net calorific value and carbon emission factor. Besides, in order to draw carbon emission per PKM for each mode for further analysis, passenger volume and average trip distance of each transport mode are also required.

\subsubsection{Data gathering}

Based on the literature (National Bureau of Statistics of China, 2012), Beijing's average car population in 2012 was 4.51 million (averaged with the car population at the beginning and at the end of 2012), all of which run on gasoline. This work carried out stratified sampling investigation, which select samples from subgroups of vehicle types according to its share, and obtained 2000 groups of data, from which weighted average annual VKT and energy efficiency of cars were derived, as shown in Table 1.The annual car person-trips are 6.14 billion, and the average trip distance is $11.5 \mathrm{~km}$ (Beijing Transportation Research Center, 2012).

Table 1. Weighted average VKT and energy efficiency of cars in Beijing in 2012

\begin{tabular}{cccc}
\hline Items & $\begin{array}{c}\text { Average annual } \\
\text { VKT }(\mathrm{km})\end{array}$ & $\begin{array}{c}\text { Average annual VKT per } \\
\text { Vehicle }(\mathrm{km})\end{array}$ & $\begin{array}{c}\text { Average energy efficiency } \\
(\text { L gasoline } / 100 \mathrm{~km})\end{array}$ \\
\hline $\begin{array}{c}\text { Organization cars } \\
\text { Private cars }\end{array}$ & 22016 & 12391 & 8.82 \\
\hline
\end{tabular}

As for taxis, 235 taxi enterprises were investigated. The vehicle fleet size was 66 640. Total energy consumption was 498.96 million-liters of gasoline. Based on the literature (Beijing Transportation Research Center, 2012), annual passenger volume of taxis was 699.23 million and average trip distance was $9.30 \mathrm{~km}$. 
Table 2. Operation data of buses in Beijing in 2012

\begin{tabular}{cccc}
\hline Bus types & $\begin{array}{c}\text { Vehicle } \\
\text { population }\end{array}$ & VKT (million km) & $\begin{array}{c}\text { Energy consumption } \\
\text { (L gasoline/100 km) }\end{array}$ \\
\hline Diesel single unit bus & 12404 & 80.99 & 34.14 \\
Diesel articulated bus & 4910 & 26.78 & 44.15 \\
CNG single unit bus & 2489 & 13.52 & $36.31(\mathrm{~kg} \mathrm{CNG} / 100 \mathrm{~km})$ \\
CNG articulated bus & 755 & 3.998 & $39.25(\mathrm{~kg} \mathrm{CNG} / 100 \mathrm{~km})$ \\
$\begin{array}{c}\text { Electric bus (single unit } \\
\text { and articulated) }\end{array}$ & 660 & 3.078 & $100.45(\mathrm{kWh} / 100 \mathrm{~km})$ \\
Other types & 6884 & 6.460 & 29.04 \\
\hline
\end{tabular}

As for buses, according to the data provided by nine operation sub-companies of Beijing Public Transport Holdings Limited, different types of buses were drawn, as shown in Table 2. Since the operation companies differed from each other, results were weighted by the vehicle population of each bus type. The annual passenger volume of buses was 5.15 billion.

For rail transit, energy and passenger data are recorded by equipment. Based on data of 15 lines (excluding the lines operated after December 30, 2013) provided by the two rail transit operation companies in Beijing, the rail transit power consumption was 1044.61 million $\mathrm{kWh}$, passenger volume was 2461.62 million (according to Beijing's statistical standard, each time a passenger transfers from one line to another in the rail network, he will be counted one more time in the total volume), and the weighted average trip distance was $8.35 \mathrm{~km}$ (the statistical standard of this distance was consistent with that of passenger volume) in 2012. Data of some lines are shown in Table 3.

Table 3. Operation data of rail transit in Beijing in 2012 (partial)

\begin{tabular}{cccccc}
\hline Lines & $\begin{array}{c}\text { Line } \\
\text { length } \\
(\mathbf{k m})\end{array}$ & $\begin{array}{c}\text { Main alignment } \\
\text { types }\end{array}$ & $\begin{array}{c}\text { Passenger } \\
\text { volume (million } \\
\text { person) }\end{array}$ & $\begin{array}{c}\text { Average trip } \\
\text { distance } \\
(\mathbf{k m})\end{array}$ & $\begin{array}{c}\text { Energy consumption } \\
\text { (million kWh) }\end{array}$ \\
\hline Line 8 & 14.39 & underground & 47.05 & 6.86 & 44.84 \\
Line 9 & 11.99 & underground & 13.28. & 6.98 & 29.38 \\
Line 10 & 23.84 & underground & 317.29 & 6.98 & 102.05 \\
Line 15 & 30.45 & underground & 39.38 & 16.63 & 55.47 \\
Airport express & 26.10 & overground & 8.52 & 24.24 & 27.57 \\
\hline
\end{tabular}

\subsubsection{Parameter calculation}

Carbon emission factors of fuel have a great effect on estimation results. Four types of fuel are used in Beijing's passenger transport. According to the relevant basic parameters in IPCC 2006, the emission parameters, including that of electric energy, gasoline, diesel and CNG were derived and calibrated as follows.

1) Calibration of electric energy emission factor

The electric energy emission factor was calculated according to fossil fuel terminal consumption, which refers to carbon emission during generation from fossil fuel power plant. Since this work was not based on the methodology of CDM and did not analyze the carbon footprint, the electric emission 
factor from CDM documents (such as operating margin emission factor) or carbon footprint analysis cannot be used here. According to the emission factor calculation method in the official Chinese report (National Development and Reform Commission of China, 2013) and CDM document (UNFCCC/CCNUCC, 2011), the electricity emission factor in Beijing is derived as follows:

$$
E f_{e}=\left(\frac{i_{j}^{\left(C_{i, j} \times N c v_{i} \times E f_{C O 2, i}\right)}}{G c_{j}} \times{ }_{j}\right),
$$

where $E f_{e}$ refers to the emission factor of electricity in Beijing $(\mathrm{kg} \mathrm{CO} / \mathrm{kWh}), C_{i, j}$ denotes consumption of fuel type $i$ in electricity grid $j(\mathrm{~kg}), N c v_{i}$ is net calorific value of fuel type $i$ for fixed source in China (Kcal/ $/ \mathrm{kg}), E f_{\mathrm{CO}, i}$ is emission factor of fuel type $i$ in IPCC $2006\left(\mathrm{~kg} \mathrm{CO}_{2} / \mathrm{Kcal}\right), G c_{j}$ is the total generating capacity of electricity grid $j(\mathrm{kWh})$, and $\alpha_{j}$ refers to the sharing of power supply to the North China Grid from the electricity grid $j$ out of the total power supply of North China Grid (\%).

Because the electricity statistical data of 2012 has not been published, statistical data of 2011, as shown in table 4, has been used. With the emission factor of IPCC and Formula 2, the comprehensive electric energy emission factor of electricity in Beijing was $0.9607 \mathrm{~kg} \mathrm{CO}_{2} / \mathrm{kWh}$.

Table 4. Carbon emission data of North China Grid

\begin{tabular}{ccccc}
\hline Grid & $\begin{array}{c}\text { Carbon emission } \\
(\text { million t CO }\end{array}$ & $\begin{array}{c}\text { Generation } \\
\text { capacity } \\
\left(\mathbf{1 0}^{\mathbf{8}} \mathbf{k W h}\right)\end{array}$ & $\begin{array}{c}\text { Grid carbon } \\
\text { emission factor } \\
(\mathbf{k g} / \mathbf{k W h})\end{array}$ & $\begin{array}{c}\text { Sharing of } \\
\text { power supply }\end{array}$ \\
\hline North China Grid & 1139.23 & 11781 & 0.9670 & $96.72 \%$ \\
Northeast China Grid & 287.78 & 2962 & 0.9716 & $0.92 \%$ \\
Northwest China Grid & 321.34 & 4611 & 0.6969 & $2.67 \%$ \\
\hline
\end{tabular}

2) Calibration of emission factors of gasoline, diesel and $\mathrm{CNG}$

Using the moving source carbon emission factors in IPCC 2006 (Intergovernmental Panel on Climate Change, 2006), the net calorific value of fuels in China(National Bureau of Statistics of China,2012), and the carbon emission factors of gasoline, diesel oil, and CNG were drawn. The densities of gasoline and diesel oil are that of Chinese gasoline 93\# and diesel $+10 \#$ under $20^{\circ} \mathrm{C}$, respectively. The density of $\mathrm{CNG}$ was $0.654 \mathrm{~kg} / \mathrm{m}^{3}(288.15 \mathrm{~K}, 101.325 \mathrm{kPa})$, which is the average density of G20 and G23(General Administration of Quality Supervision,2012). The moving source carbon emission factors of three fuels in China were achieved with formula 3, shown in Table 6.

$$
E f_{j}=E f_{I P C C, j} \cdot N C V_{j} \cdot D_{j},
$$

In the formula, $E f_{I P C C, j}$ refers to emission factor of fuel type $j$ in IPCC, $N C V_{j}$ and $D_{j}$ denotes the net calorific value and density of fuel type $j$ in China, respectively. All the value are presented in table 5. 
Table 5. Carbon emission factors of three fuels

\begin{tabular}{ccccc}
\hline Fuel type & $\begin{array}{c}\mathbf{C O}_{2} \text { emission factor } \\
\text { in IPCC kg/TJ } \\
\text { (default) }\end{array}$ & $\begin{array}{c}\text { Chinese net } \\
\text { calorific value } \\
\text { (KJ/kg) }\end{array}$ & $\begin{array}{c}\text { Chinese fuel } \\
\text { density }(\mathbf{k g} / \mathbf{L})\end{array}$ & $\begin{array}{c}\mathbf{C O}_{2} \text { emission } \\
\text { factor (kg/L) }\end{array}$ \\
\hline Gasoline & 69300 & 43040 & $0.725 \mathrm{~kg} / \mathrm{L}$ & 2.162 \\
Diesel & 74100 & 42652 & $0.850 \mathrm{~kg} / \mathrm{L}$ & 2.686 \\
CNG & 56100 & $38931 \mathrm{KJ} / \mathrm{m}^{3}$ & $0.654 \mathrm{~kg} / \mathrm{m}^{3}$ & $3.340 \mathrm{~kg} / \mathrm{kg}$ \\
\hline
\end{tabular}

\section{Results and Discussions}

Based on the data and emission model, the total passenger transport carbon emission in Beijing in 2012 was estimated as 15.00 million tonnes of $\mathrm{CO}_{2}$. The carbon emission structure of passenger transport in Beijing and emission per PKM of different transport modes is analyzed in detail.

\subsection{Comparison Analysis of the Results}

Comparison of the calculation results with other works should be analyzed to ensure that it is meaningful for further discussion. However, the verification of emissions is difficult because there are no correct results to be compared with. At first we tried to verify the results with the carbon emission drawn directly from oil apparent consumption in Beijing, but oil consumption contained fuel consumption of freight transportation, which was not possible to be split. Finally, the verification was done through comparing the results with other works.

For the total emission, one existing work estimated the carbon emission of transportation in Beijing in 2009 is 14.54 million tonnes of $\mathrm{CO}_{2}, 11.95$ of which is from passenger transportation (Beijing Jiaotong University, 2012). The result is lower than that in this work, because in 2009 Beijing's vehicle population and rail track length were smaller. And also, their work used the officially released vehicle fuel efficiency, which is much higher than that taken from drivers by questionnaire. Considering these reasons, the results are comparable with others' outcome.

For the carbon emission factors in terms of PKM, emission factors of various modes in current research were collected, extracted and compared with that drawn in this work. Although this factor varied greatly from case to case due to differences of load factor and vehicle technology, the comparison of factors from different work still reveals something. Data in table 6 demonstrate that emission factors got in this work are very close to that in other research for Beijing. All the factors from USA are higher than that we calculated because of lower load factor. Compared to Shanghai, emission factor of Beijing's taxis is much lower while that of cars is much higher. The difference can be ascribed to the methodology and the parameters used in the study of Shanghai (Li et al., 2012), which applied top-down method. When the total emissions were divided by PKM, average trip distance of $6 \mathrm{~km}$ for taxis and $20 \mathrm{~km}$ for cars were accessed from very small samples, which are quite questionable. In Beijing, the average trip distance for taxis and cars are $9.30 \mathrm{~km}$ and $11.5 \mathrm{~km}$, respectively. Shanghai and Beijing are the first two large cities with multi-centers in China, and travel patterns of cars and taxis probably do not differ so much even there are geographical differences. It is 
highly possible that shorter trip distance leads to larger emission factor for taxis, while longer trip distance averages down emission factor for cars in Shanghai in the study.

Table 6. Emission factors of various modes from current research and this work

\begin{tabular}{ccccc}
\hline \multirow{2}{*}{ Modes } & \multicolumn{4}{c}{ Emission factors $\left(\mathbf{g ~ C O}_{2} / \mathbf{P K M}\right)$} \\
\cline { 2 - 5 } & Beijing & Shanghai & USA & Beijing (this work) \\
\hline Buses & 35 & 55.5 & 183.2 & 28.60 \\
Cars & 178.6 & 101.9 & 270.6 & 160.40 \\
Taxis & 178.6 & 254.6 & & 165.98 \\
Rail transit & 42 & 79.6 & 67.6 & 48.85 \\
\hline
\end{tabular}

Sources: Data of existing research for Beijing (Beijing Jiaotong University, 2012; Xiao et al., 2011); Data for Shanghai (Li et al., 2012); USA data (Hodges, 2010)

\subsection{Mode Sharing of Passenger Transport Carbon Emission in Beijing}

According to the results, carbon emission of buses, cars, taxis, and rail transit were drawn, as shown in Table 7. The carbon emission of car is the largest and reaches 11.33 million tonnes, while that of rail transit is the least at only 1 million tonnes. The efficiency of different transport modes can be demonstrated by comparing the share of passenger volume and carbon emission of all the transport modes in 2012, as shown in Table 7 and Figure 2. Passenger volume share of cars is only 39\%, while carbon emission share of cars reaches $75.5 \%$. On the contrary, passenger volume share of rail transit is $20 \%$, and its share of carbon emission is just $6.7 \%$. Therefore, rail transit and buses are much more efficient than cars and taxis.

Table 7. Sharing and carbon emission of transport modes in Beijing in 2012

\begin{tabular}{|c|c|c|c|c|}
\hline $\begin{array}{l}\text { Transport } \\
\text { modes }\end{array}$ & $\begin{array}{c}\text { Carbon emission } \\
\text { (million tonnes of } \\
\mathrm{CO}_{2} \text { ) }\end{array}$ & $\begin{array}{l}\text { Passenger volume } \\
\text { (billion persons) }\end{array}$ & $\begin{array}{c}\text { Sharing of } \\
\text { carbon emission }\end{array}$ & $\begin{array}{c}\text { Sharing of } \\
\text { passenger } \\
\text { volume } \\
\end{array}$ \\
\hline Buses & 1.59 & 5.15 & $10.60 \%$ & $35.64 \%$ \\
\hline Cars & 11.33 & 6.14 & $75.53 \%$ & $42.51 \%$ \\
\hline Taxis & 1.08 & 0.70 & $7.20 \%$ & $4.84 \%$ \\
\hline Rail transit & 1.00 & 2.46 & $6.67 \%$ & $17.02 \%$ \\
\hline \multicolumn{5}{|c|}{$\begin{array}{l}\text { Carbon emission: million tons of } \mathrm{CO}_{2} \\
\text { Passenger volume: billion passenger }\end{array}$} \\
\hline & 5 & & & \\
\hline & Buses & Taxis & Rail Transit & \\
\hline
\end{tabular}


Figure 2. Passenger volume and carbon emission of different transport modes

\subsection{Emission per PKM for Different Modes}

To evaluate the emission intensity of each transport mode, not only emission per VKT of a particular mode needs to be considered, but also the passenger capacity of that transport mode and the average trip distance for each passenger should be taken into account. Therefore, carbon emission per PKM was set as an index. Based on the calculation of carbon emissions in this work and the average trip distance of each transport mode, the emission intensity of each transport mode was drawn with the current load factors in Beijing, as shown in Table 8 and Figure 3.

Table 8. Emission factors of various passenger transport modes

\begin{tabular}{ccccc}
\hline $\begin{array}{c}\text { Transport } \\
\text { modes }\end{array}$ & $\begin{array}{c}\mathbf{C O}_{2} \\
\text { emissions } \\
\text { (million } \\
\text { tonne) }\end{array}$ & $\begin{array}{c}\text { Passenger } \\
\text { volume } \\
\text { (billion } \\
\text { person) }\end{array}$ & $\begin{array}{c}\text { Average trip } \\
\text { distance }(\mathbf{k m})\end{array}$ & $\begin{array}{c}\text { Emission factors } \\
(\mathbf{g ~ C O} / \mathbf{P K M})\end{array}$ \\
\hline Bus & 1.59 & 5.15 & 10.80 & 28.60 \\
Cars & 11.33 & 6.14 & 11.50 & 160.40 \\
Taxis & 1.08 & 0.7 & 9.30 & 165.98 \\
Rail Transit & 1 & 2.46 & 8.35 & 48.85 \\
\hline
\end{tabular}

Table 8 demonstrates that with the current load factor, carbon emission per PKM of taxis is the highest in Beijing, which is ascribed to the high empty loading rate. The next is that of cars. Unlike several existing results (Hodges, 2010; Australian Greenhouse Office, 2007), emission factor of rail transit in terms of PKM drawn in this work is $48.85 \mathrm{~g} \mathrm{CO}_{2}$, which is higher than that of buses by 20.25 $\mathrm{g}$. This is mainly because the station power consumption of rail transit was taken into account, and the carbon emission factor for electricity is drawn from local grid. Among the four modes, carbon emission efficiency of public transit is much higher than that of cars or taxis.

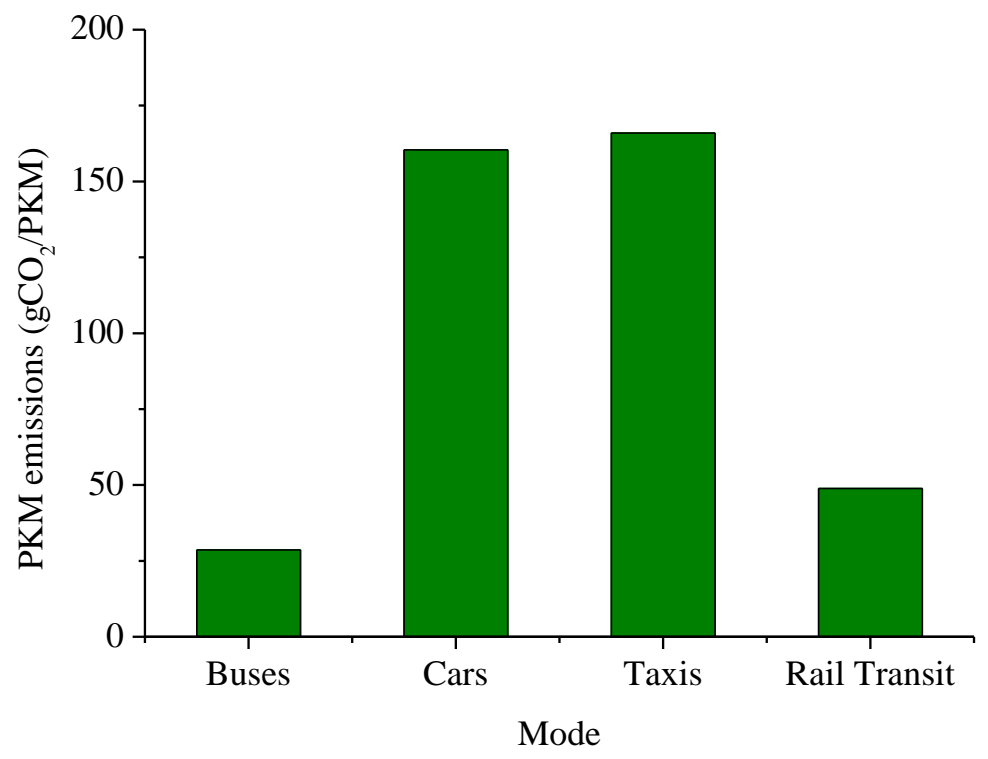

Figure 3. PKM Emissions of different transport modes 
A particular point about the results should be specified. Currently about $80 \%$ of rail network in Beijing is underground. The station environment control system of underground rail transit is very complicated and energy consuming, and air resistance in the tunnel is huge. Under this situation, the energy consumption and carbon emission of underground rail transit is twice that of overground line. For individual transit line, the PKM emission factor of whole overground Line 13 in Beijing is lower than that of buses at $24.55 \mathrm{gCO}_{2}$, while with the same load rate, the PKM emission factor of underground Line 4 is $54.83 \mathrm{gCO}_{2}$.

\subsection{Potential Carbon Emission Reduction Analysis}

Based on the estimation results and the developing trend of transport structure, Beijing's passenger transport is an important potential carbon emission reduction target. In fact, the developing trend of Beijing's passenger transport structure demonstrates the possibility of carbon emission reduction, as shown in Figure 4, tailored from annual reports (Beijing Transportation Research Center, 2013). The trip share of public transit increased from $51.5 \%$ in 2003 to $59.5 \%$ in 2012 , while that of cars dropped by $4.7 \%$. This trend is expected to continue in the future.

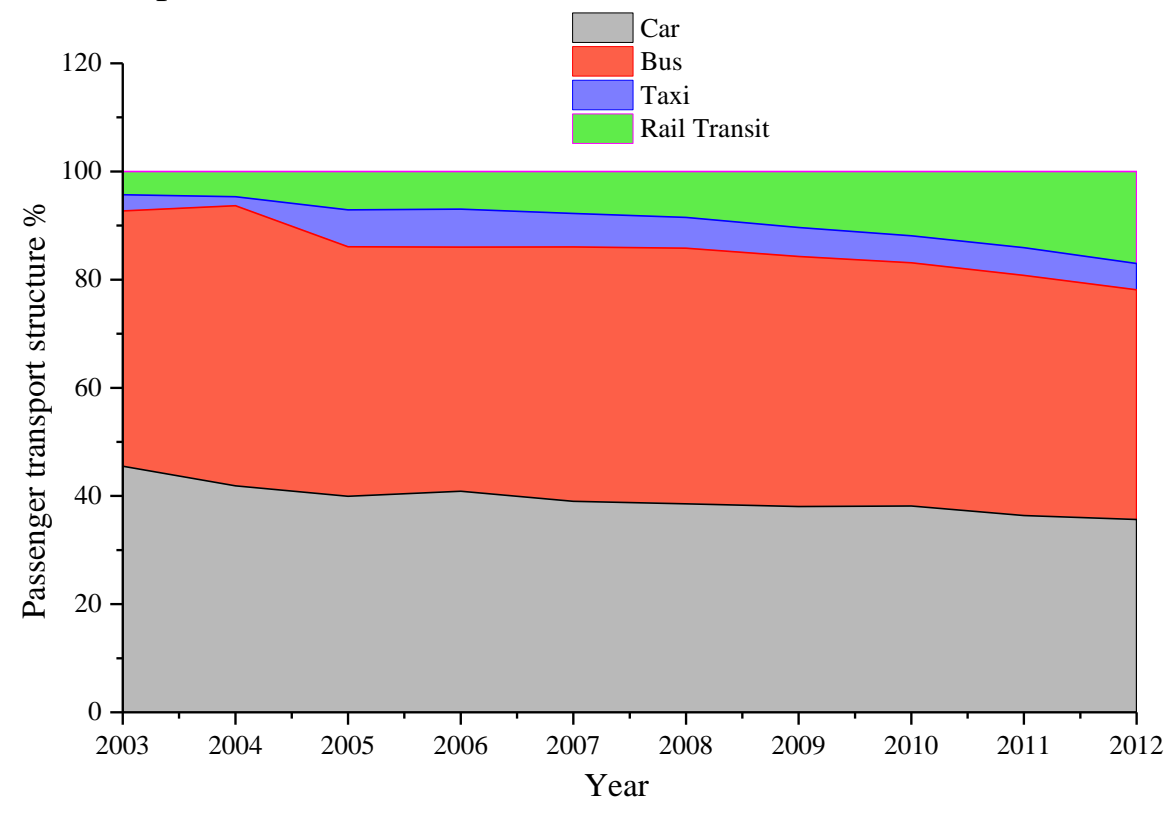

Figure 4. Mode shift trend of Beijing's passenger transport

Based on the current PKM emission factors of various modes, mode sharing, and passenger volume data in the comprehensive transport survey (Beijing Transportation Research Center, 2012), Beijing's passenger transport annual carbon emission in the last ten years was estimated, as illustrated in Figure 5, and it was noted that $\mathrm{CO}_{2}$ emissions increased rapidly from 9.38 million tonnes in 2003 to 15 million tonnes in 2012. However, with rapidly developing of public transit sharing, the total emissions held little increment and even declined in the last 3 years. 


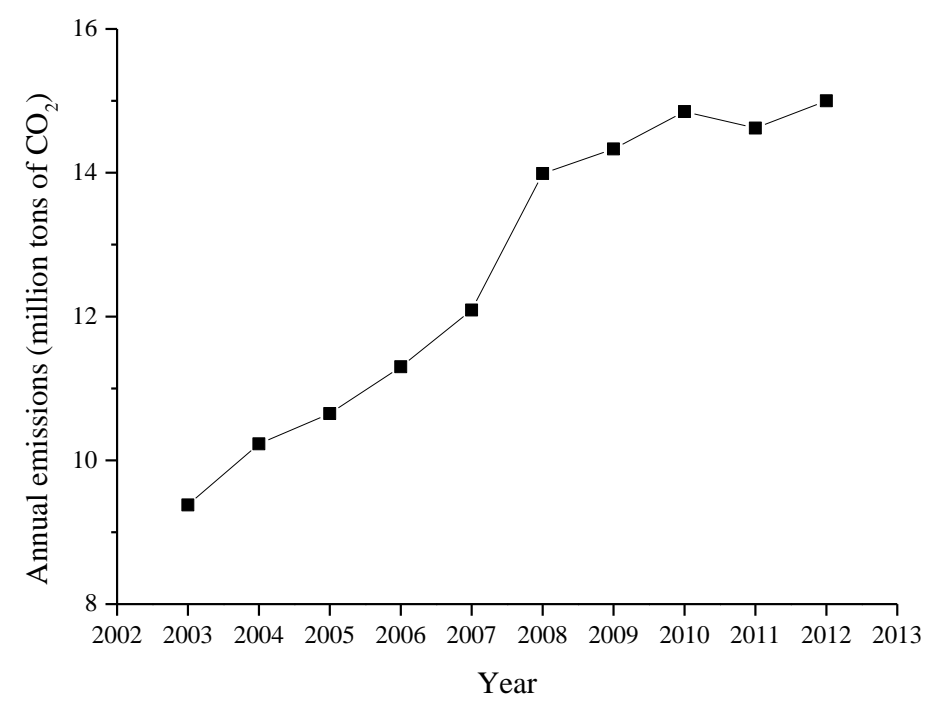

Figure 5. Carbon emissions of Beijing's passenger transport in last decade

According to current policy planning, in the next few years Beijing is set to emphasize the development of rail transit, building a rail network of $1000 \mathrm{~km}$ to increase the share of public transport (Beijing Municipal Commission of Urban Planning, 2013). At the same time, measurements have been implemented to reduce car share, such as limiting car purchase by lottery within 10 thousand per month, controlling each car from usage for one weekday per week. To further control car usage, congestion charge will probably be adopted in the near future (Creutzig and He, 2009). Based on mode sharing of passenger transport in metropolitan areas of developed countries, Beijing's passenger traffic mode sharing targets for 2020 are as follows: public transport, including rail transit and buses with equal sharing, to account for $70 \%$ of motorized travel; $25 \%$ share of cars; and the rest by taxis (Beijing Municipal Commission of Urban Planning, 2013). According to the developing trend of annual trips in Beijing (Beijing Transportation Research Center, 2012), motorized travel in Beijing in 2020 is predicted to be 17.51 billion. According to the target above, the carbon emission of passenger transport in Beijing in 2020 is projected to be 13.82 million tonnes of $\mathrm{CO}_{2}$ using the current fuel efficiency and electricity emissions factor. Compared to total emissions under the current mode sharing, which stands at 18.12 million tonnes of $\mathrm{CO}_{2}, 4.39$ million tonnes of $\mathrm{CO}_{2}$ emission reduction is set to be achieved.

\subsection{Comparison with the Emission of other cities in the World}

Comparison of Beijing's emissions with that of other cities in the world is helpful for emission mitigation policy making. To this end, latest emission of urban transportation of the cities in Continental Europe (Carney et al., 2009), the UK (Ricardo-AEA, 2013) and American (Dickinson et al., 2013) were collected, which are presented in Figure 6. However, most of the released emission inventories do not provide the details of the estimation, such as transport modes covered, so it is difficult to split emissions exactly according to the scope of this work. But a general comparison without considering background information still can tell us something about the current emission of Beijing. As shown in Figure 6, Beijing's transport carbon emission is still relatively large. Developed countries have long been well aware of the problem and are actively seeking for ways to reduce 
emission and some laws have already been passed to make strategies for GHG mitigation. Beijing has a great potent to reduce emission learning from the experience.

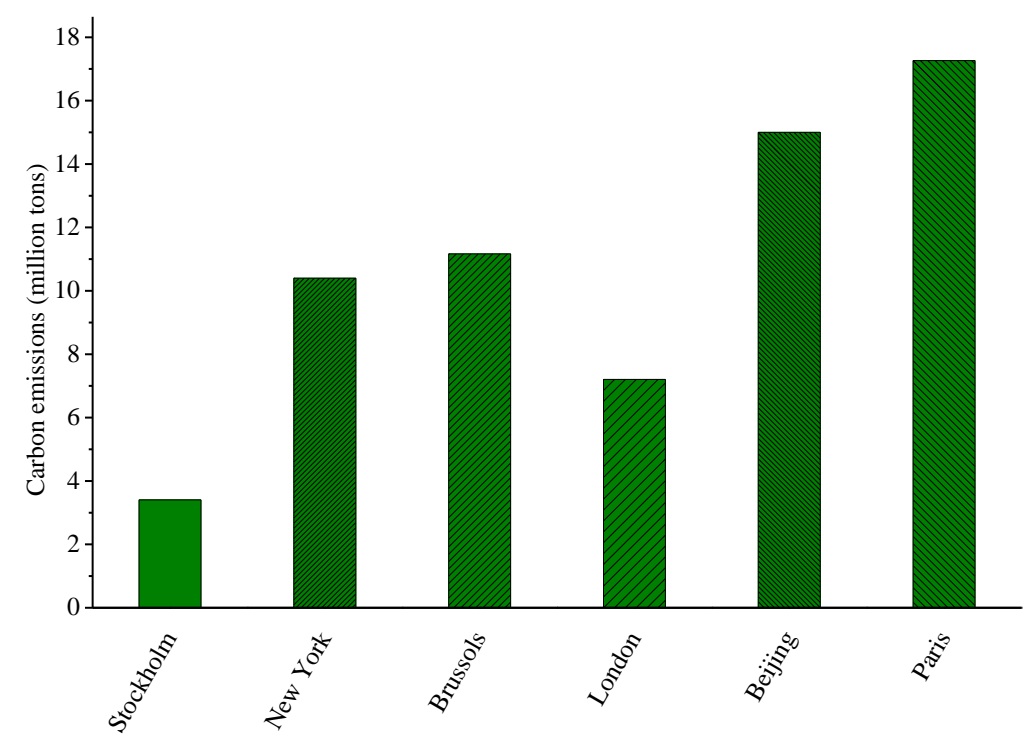

Figure 6. Carbon emissions from passenger transportation of different cities

\section{Conclusion}

This paper established a carbon emission model for urban passenger transport for a typical city in a developing country based on the definition of calculation scope and transport characteristics in developing counties. Relevant data was collected and parameters were calibrated according to the local situation. In contrast with existing research, this work provided a methodology with more accurate parameters, especially for carbon emission factor of electricity. Based on the emission model and estimation results, the following conclusions were drawn:

(1) The carbon emission from passenger transport in Beijing in 2012 was 15 million tonnes of $\mathrm{CO}_{2}$, and $75.5 \%$ was from cars. Car trips are the main target of carbon emission reduction.

(2) Public transport is relatively efficient and its carbon emission only accounted for $17.3 \%$ of total emissions, while comprising $52.7 \%$ of total residential trips.

(3) With the current technical condition and load factor, the PKM carbon emissions of cars and taxis are five times higher than that of buses. On taking into account station energy and carbon emission of electricity, the PKM emission of rail transit is about $20 \mathrm{gCO}_{2}$ higher than that of buses.

(4) Assuming the trip distance of each mode is constant, if the share of public transport in Beijing increases by $17.3 \%$ while that of car reduces by $17.5 \%$, carbon emission reduction of 4.93 million tonnes of $\mathrm{CO}_{2}$ can be achieved in 2020 .

\section{Acknowledgments}

This work was sponsored by the project "Calculation of Carbon Emission Reduction of Beijing Rail Transit ant Its Interchange Facilities" from Beijing Infrastructure Investment Co., LTD, China. The authors acknowledge the support received from Beijing Subway Operation Company, Beijing MTR 
Corporation Limited, Beijing Public Transport Holdings Limited, and the taxi companies in Beijing for data collection.

\section{Conflicts of Interest}

The authors declare no conflict of interest.

\section{References and Notes}

Aliakbar K., Ali V. and Ahmed K.(2012). An estimation of traffic related $\mathrm{CO}_{2}$ emissions from motor vehicles in the capital city of Iran. Iran J Environ Healt, 9:13

Anas, A., Timilsina, R., Zheng, S. (2009). An analysis of various policy instruments to reduce congestion, fuel consumption and $\mathrm{CO} 2$ emissions in Beijing. World Bank Policy Research Working Paper, (5068).

Australian Greenhouse Office. (2007). National Greenhouse Gas Inventory: Analysis of Recent Trends and Greenhouse Indicators 1990 to 2005. Australian Greenhouse Office in the Department of the Environment and Water Resources. Available from:

http://pandora.nla.gov.au/pan/81483/20080211-

1432/www.greenhouse.gov.au/inventory/2005/pubs/trends2005.pdf [accessed on 15 Feb. 2013]

Beijing Jiaotong University. (2012). Study of the low carbon transport development in Beijing (in Chinese). Second Beijing environment project supported by World Bank Group.

Beijing Municipal Commission of Urban Planning. (2013). Beijing's Urban Rail Transit Construction Plan (2014-2020)

Beijing Transportation Research Center. (2013). Beijing traffic development annual report(in Chinese).

Beijing Transportation Research Center. (2012), Beijing Transport Committee. Beijing the $4^{\text {th }}$ comprehensive transport survey.

Board, C. E. (2011). Approved consolidated baseline and monitoring methodology ACM0016 "Mass Rapid Transit Projects". UNFCCC/CCNUCC. Available from: https://cdm.unfccc.int/methodologies/DB/8PBZENI1PK0QIJW8RJ5LEDXV6WX60O (accessed on 15 Feb. 2013)

Carney, S., Green, N., Wood, R.,and Read, R. (2009). Greenhouse gas emissions inventories for 18 European regions. Available from: http://www.euco2.eu/resources/GRIP-Broschuere-Small.pdf. [accessed on 1 Dec. 2013]

CHANGE, I. I. P. O. C. (2006). Guidelines for National Greenhouse Gas Inventories. Intergovernmental Panel on Climate Change. Available from: http://www.ipcc-nggip.iges.or.jp/public/2006gl/ [accessed on 10 Sep. 2010]

Creutzig, F., and He, D. (2009). Climate change mitigation and co-benefits of feasible transport demand policies in Beijing. Transportation Research Part D: Transport and Environment, 14(2), 120-131.

Dickinson J., Khan J., Amar M. (2013). Inventory of New York City Greenhouse Gas Emissions, City of New York, Mayor's Office of Long-Term Planning and Sustainability, New York, 2013. Available from: 
http://nytelecom.vo.llnwd.net/o15/agencies/planyc2030/pdf/greenhousegas_2013.pdf[accessed on 3 Mar. 2014]

General Administration of Quality Supervision, Inspection and Quarantine of China. (2012).Test methods for fuel consumption of CNG vehicles (in Chinese), GB/T 29125-2012.

Grant, M. D., Choate, A., \& Pederson, L. (2008). Assessment of greenhouse gas analysis techniques for transportation projects. In Transportation Research Board 87th Annual Meeting (No. 08-2688).

He D., Meng F., Wang M. (2011). Impacts of Urban Transportation Mode Split on $\mathrm{CO}_{2}$ Emissions in Jinan, China. Energies, 4, 685-699.

He H., Huo H.,Zhang Q.,He D.Q.,etc.(2005). Oil consumption and $\mathrm{CO}_{2}$ emissions in China's road transport: current status, future trends, and policy implications. Energy Policy, 33, 1499-1507.

Hodges T. (2010). Public Transportation's Role in Responding to Climate Change. U.S. Department of Transportation, Federal Transit Administration. Available from:

http://www.fta.dot.gov/documents/PublicTransportationsRoleInRespondingToClimateChange201 0.pdf [accessed on 15 Feb. 2013]

Intergovernmental Panel on Climate Change (IPCC) (2006). 2006 Guidelines for National Greenhouse Gas Inventories. Prepared by the National Greenhouse Gas Inventories Programme. Tokyo, Japan: Institute for Global Environmental Strategies.

Li L., Hu J., Shao D. (2012). Effects of accelerated development of urban rail transit in Shanghai before the World Expo on greenhouse gas emission reduction. China Environmental Science, 32(6):1141-1147. (in Chinese).

Lisa R., Madhav P.(2010).Urban mobility forecasts: emissions scenarios for three Indian cities. In: TRB annual meeting, 11 Jan. 2010.

National Bureau of Statistics of China.(2012). China energy statistical yearbook 2012(in Chinese); China Statistics Press, Beijing, P. R. China; pp: 353.

National Development and Reform Commission of China.(2013). 2013 Baseline Emission Factors for Regional Power Grids in China.(in Chinese).

Nejadkoorki F., Nicholson K., Lake I., Davies T. (2008).An approach for modeling $\mathrm{CO}_{2}$ emissions from road traffic in urban areas. Sci Total Environ, 406:269-278.

Olivier, J. G. (2013). The huge trends in global $\mathrm{CO}_{2}$ emissions: 2013 report. PBL Netherlands Environmental Assessment Agency. Available from: http://www.pbl.nl/sites/default/files/cms/publicaties/pbl-2013-trends-in-global-co2-emissions2013-report-1148.pdf [accessed on 20 Nov. 2013]

Ricardo-AEA. ( 2013). Local and Regional CO2 Emissions Estimates for 2005-2011 - CO2 emissions within the scope of influence of Local Authorities (previously called National Indicator 186: Per capita CO2 emissions in the LA area), London: Department of Energy and Climate Change. Available from:

https://www.gov.uk/government/uploads/system/uploads/attachment_data/file/212448/Copy_of_Subse t_Datatables.xlsx [accessed on 11 Sep., 2013].

Transport for London. (2013). Travel in London, Report 6.

https://tfl.gov.uk/cdn/static/cms/documents/travel-in-london-report-6.pdf [accessed on 30 Sep., 2015]

Wang Z., Chen F. and Shi Z. (2013). Prediction on Medium and Long Term Energy Consumption of Urban Rail Transit Network in Beijing. China Railway Science, 4(3): 133-136. (in Chinese). 
Xiao Z., Cai Y., Liu Z. (2011). Quantitative Distribution and Related Factors for Household Daily Travel $\mathrm{CO}_{2}$ Emissions in Beijing. Urban Studies, 18(9):104-112. (in Chinese). 